\title{
Uterine leiomyoma presenting with unusual pathological features: a series of two cases
}

\author{
Garima Singh, Nidhi Verma, Sompal Singh, Namrata Nargotra*
}

Department of Pathology, NDMC Medical College \& Hindu Rao Hospital, Delhi, India

Received: 17 February 2016

Accepted: 12 March 2016

\section{*Correspondence:}

Dr. Namrata Nargotra,

E-mail: drnamrata50@gmail.com

Copyright: $\odot$ the author(s), publisher and licensee Medip Academy. This is an open-access article distributed under the terms of the Creative Commons Attribution Non-Commercial License, which permits unrestricted non-commercial use, distribution, and reproduction in any medium, provided the original work is properly cited.

\begin{abstract}
Leiomyomas are benign and most common smooth muscle neoplasms that can occur in any organ, most commonly in uterus, small bowel and esophagus. Leiomyomas may have unusual presentations either in form of location or various secondary changes like hyaline, myxoid, red degeneration, chondroid metaplasia, sarcomatous change, etc. We present two unusual cases of leiomyomas, one involving an unusual location (giant cervical fibroid) and the other a uterine leiomyoma with rare pure chondroid metaplasia. Both these entities are rare and hold importance in the differential diagnosis because it is imperative to differentiate the giant cervical fibroid from any ovarian neoplasm or procidentia and chondroid metaplasia from any other mesenchymal/mixed uterine tumor. Moreover giant leiomyomas require expert hands during surgical removal.
\end{abstract}

Keywords: Leiomyoma, Cervical, Uterine, Chondroid metaplasia

\section{INTRODUCTION}

Leiomyoma is the most common pelvic tumor which occurs in women of reproductive age group and very rarely below the age of 18 years. Uterine leiomyomas are benign smooth muscle neoplasms that arise from the myometrium. They are asymptomatic in $50 \%$ of cases. ${ }^{1}$ Cervical leiomyoma accounts for $0.4 \%$ of all leiomyomas. ${ }^{2}$ A cervical leiomyoma is usually single and often it is either interstitial or subserous, rarely it is submucous or pedunculated. ${ }^{3}$ Cervical fibroids are similar to other fibroids present in the uterus. According to location leiomyomas are classified into: intramural $(70 \%)$, subserosal $(20 \%)$ submucosal $(10 \%)$. Various secondary changes that may be seen in leiomyomas like: hyaline or myxoid degeneration (most common-60\%), cystic degeneration, dystrophic calcification, red degeneration, malignant change $(<1.0 \%){ }^{4}$

Histopathological variants of leiomyomas like atypical, cellular, mitotically active, myxoid, and epithelioid leiomyoma have been described. Although rare, leiomyoma may contain heterologous elements such as fat, skeletal muscle, chondroid and osseous tissues. Adipose tissue is the most common heterologous component in leiomyoma, which is then called a lipoleiomyoma. ${ }^{5,6}$ Pure cartilaginous metaplasia is very rare. Large cervical leiomyomas are difficult to handle and need an expert hand to operate these cases.

Here we are presenting two cases of leiomyomas, one a giant cervical fibroid and the other, with pure chondroid metaplasia.

\section{CASE REPORT}

\section{Case 1}

A 50 year old multiparous female patient presented with complains of menorrhagia for past 4 months and increased urinary frequency for past 2 months. Her general and systemic examinations were within normal limits. Per speculum and per vaginum examination revealed a growth inside the endocervical canal measuring approximately $7.5 \times 7 \times 5 \mathrm{~cm}$ reaching up till internal os. Growth was firm in consistency. Both 
fornices were clear. Uterus was anteverted and pushed upwards. Ultrasound showed a hypoechoic myomatous polyp in endocervical canal with well circumscribed margins. The patient was planned for surgery. Hysterectomy with bilateral salpingoopherectomy was performed and the specimen was sent for histopathology. On gross examination, uterus was $4 \times 4 \times 3 \mathrm{~cm}$ in size and endocervical canal was dilated and elongated. A large well circumscribed growth measuring $8.5 \times 7.5 \times 6.5 \mathrm{~cm}$ was attached to the endocervical canal. The mass was firm in consistency. Cut surface showed whorled appearance. Bilateral adnexa were unremarkable (Figure 1 and 2). Histopathological examination of the growth confirmed the diagnosis of leiomyoma (Figure 3 and 4).

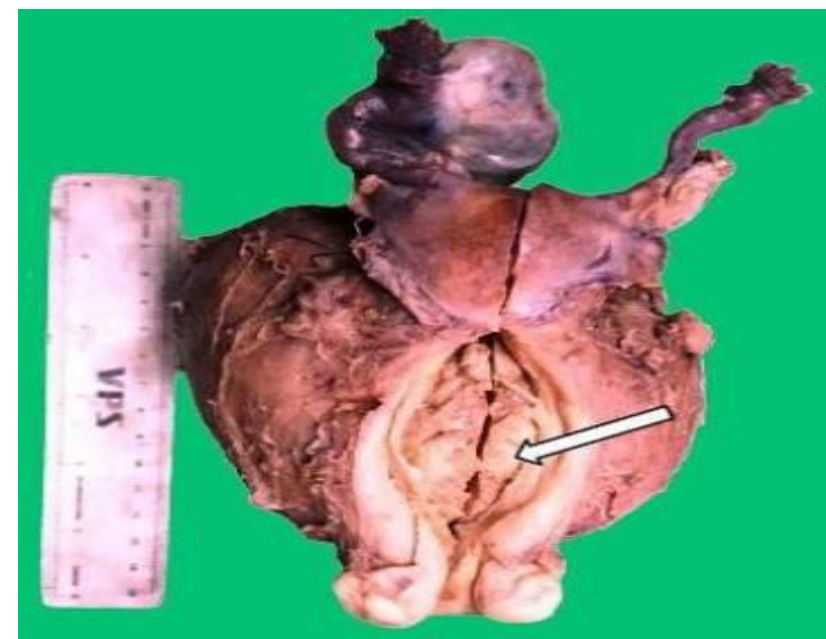

Figure 1: Gross specimen of cervical leiomyoma showing large cervical fibroid occupying entire endocervical canal and reaching uptil internal OS. Endocervical canal appears dilated and elongated whereas uterus and bilateral adnexa appears unremarkable.

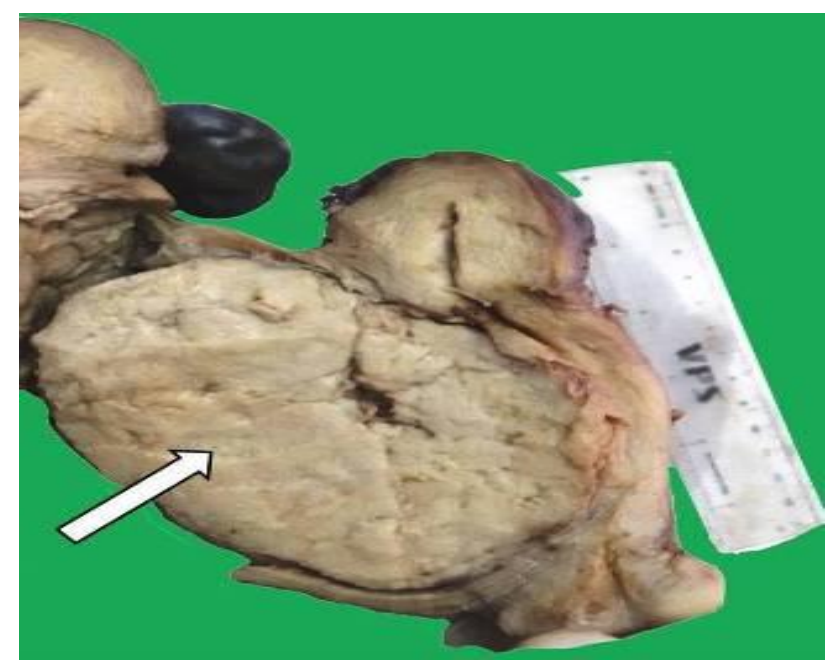

Figure 2: Cut surface of gross specimen showing cervical leiomyom with well-defined margin and whorled appearance. Uterus is pushed upwards.

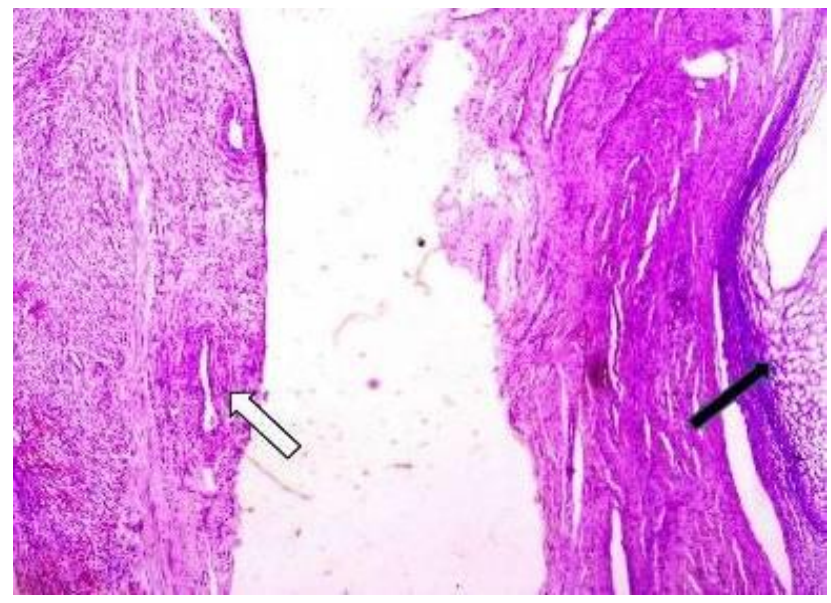

Figure 3: Microphotograph showing intracervical leiomyoma (shown by white arrow). The ectocervix present on right side (shown by black arrow) (HE 40X).

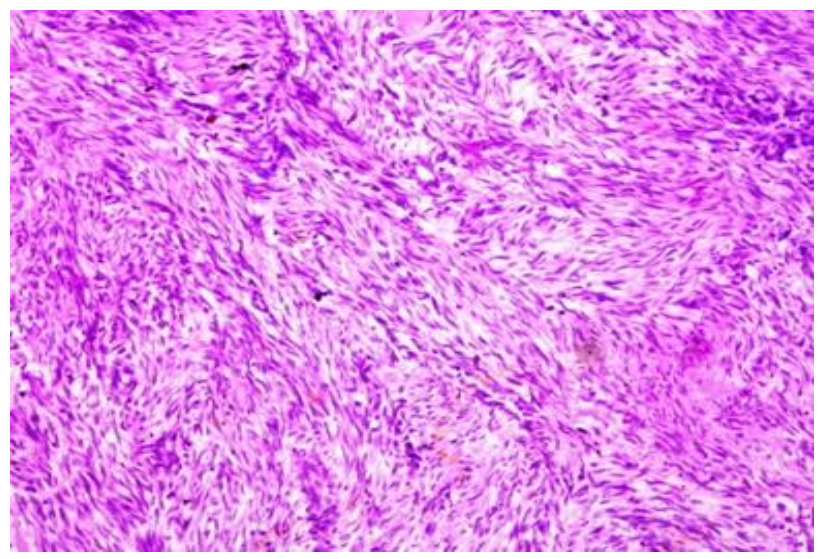

Figure 4: Microphotograph showing high power view of cervical leiomyoma comprising of interlacing fascicles of smooth muscle cell (HE 400X).

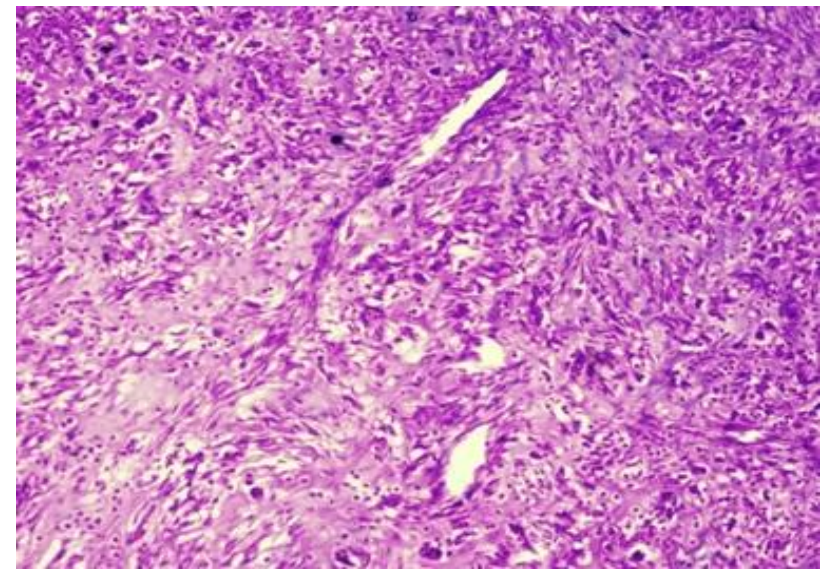

Figure 5: Microphotograph showing areas of heterologous element (mature hyaline cartilage) interspersed with fascicles of smooth muscle cells (HE 100X). 


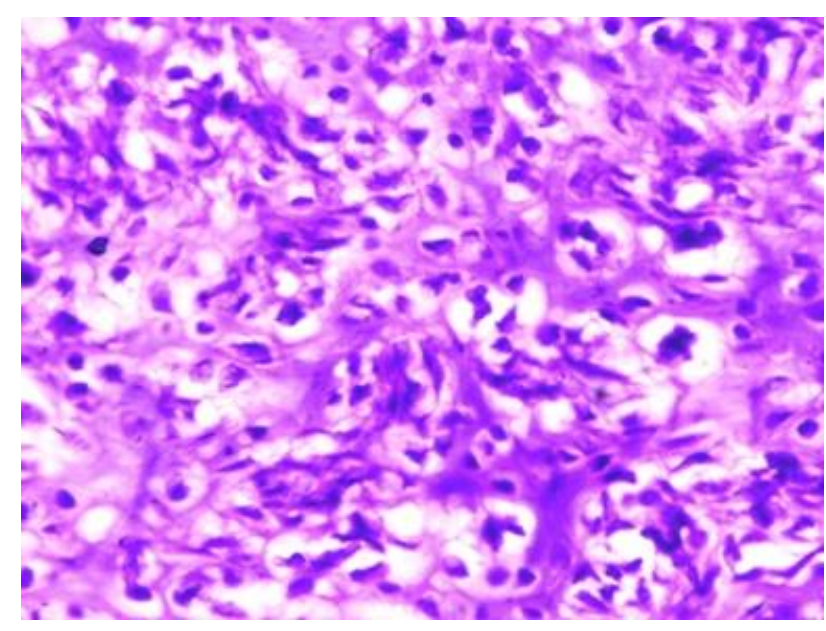

Figure 6: Microphotograph showing areas of heterologous element (mature hyaline cartilage) ( $\mathrm{HE}$ 100X).

\section{Case 2}

A 45 years female presented with complain of menorrhagia for past 2 years. Her general and systemic examinations were within normal limits. Per vaginal examination revealed an anteverted 8 week size uterus with clear fornices. Ultrasonography of abdomen showed multiple fibroids in anterior and posterior wall of uterus, ranging in size from $1-2.5 \mathrm{~cm}$ in diameter. Hysterectomy was performed and the specimen was sent for histopathology. Grossly uterus with cervix measured $11 \times 8 \times 4 \mathrm{~cm}$ in size. On serial slicing multiple intramural fibroids ranging in size from 1 to $2.5 \mathrm{~cm}$ in diameter were seen. Fibroids were firm in consistency and cut surface showed whorled appearance. Microscopic examination revealed one of the leiomyoma $(2.5 \mathrm{~cm}$ in size $)$ with islands of mature hyaline cartilage occupying approximately $50 \%$ of tumour area, interspersed in between interlacing fascicles of smooth muscle cells (Figure 5 and 6).

\section{DISCUSSION}

Leiomyoma uterus is the most common pelvic tumor which is dependent on estrogen for its growth. It commonly occurs in middle aged females. Large uterine fibroids can cause pain, constipation, frequency of urination and increased menstrual pain and irregularity, however, approximately $50 \%$ are asymptomatic. ${ }^{1}$

Uterine leiomyomas can present as single or multiple mass lesion and are classified according to location into intramural, submucosal and serosal types. The largest uterine fibroid ever reported in the medical literature weighed $63.3 \mathrm{~kg}$ and was removed postmortem in $1888{ }^{7}$ Giant cervical leiomyoma are rare. The presentation of large cervical fibroid has been reported as abdominal mass, incarcerated procidentia, uterine inversion, cervical malignancy etc. 89 In some cases, cervical fibroid may grow rapidly and can obstruct the cervix. Cervical fibroids develop in the wall of cervix and can change the shape of the cervix or may lengthen it. In case of giant cervical fibroid uterus can be pushed upwards. Large cervical fibroid can lead to urinary retention, urinary frequency, constipation, menstrual abnormalities, dyspareunia, and sometimes post coital bleeding. Pedunculated subserosal leiomyomas can most commonly simulate ovarian neoplasms, but even extensively degenerated submucus myomas may also present as ovarian tumors. In our case due to its large size, increased urinary frequency was the presenting complaint however no bowel complains were present. Due to large size, endocervical canal was dilated and elongated. Unlike uterine fibroids, cervical fibroids generally don't affect women's fertility although cervical fibroids with pregnancy are rare.

Various modalities can be used including ultrasonography (75\% accurate) and magnetic resonance imaging $(100 \%)$ to diagnose leiomyoma. Treatment of cervical fibroid is either hysterectomy or myomectomy.

Leiomyoma is a benign smooth muscle tumor of uterus which has predominantly fasicular arrangement of tumor cells. Various heterologous elements seen in leiomyomas are fat, skeletal muscle, chondroid and osseous tissues. A spectrum of histologic variants has been noted, however, metaplasia in the leiomyoma is a rare phenomenon. Adipose metaplasia is the most commonly reported metaplasia. Cause for cartilage metaplasia is not known, but it is postulated by some that it is the result of a reprogramming of stem cells that are known to exist in normal tissues, or of undifferentiated mesenchymal cells present in connective tissue. In a metaplastic change, these precursor cells differentiate along a new pathway. ${ }^{10}$ unlike dysplasia these metaplastic changes do not have malignant potential. But their presence may lead to consideration of differential diagnosis of other mesenchymal tumors which show heterologous mesenchymal elements. Cartilaginous metaplasia of leiomyomas of soft tissue is common but uterine leiomyomas with cartilaginous metaplasia is a very rare phenomenon. Our case showed multifocal areas of cartilaginous metaplasia occupying approximately $50 \%$ of tumor area.

\section{CONCLUSIONS}

We conclude that although common tumours; leiomyomas may have unusual presentations which may lead to unusual symptoms or may show presence of rare heterologous element hence mimicking other soft tissue tumours.

\section{Funding: No funding sources \\ Conflict of interest: None declared \\ Ethical approval: Not required}




\section{REFERENCES}

1. Parker WH. Etiology, symptomatology, and diagnosis of uterine myomas. Fertil Steril. 2007;87(4):725-36.

2. Bell SW, Kempson RL, Hendrickson MR. Problematic uterine smooth muscle neoplasms. A clinicopathologic study of 213 cases. Am J Surg Pathol. 1994;18(6):535-58.

3. Kumar P, Malhotra N. Tumours of the corpus uteri. In: Jeffcoat's Principles of Gynaecology. New Delhi: Jaypee Brothers Medical Publisher (Pvt.) Ltd. 2008:487-516.

4. Kawakami S, Togashi K, Konishi I, Kimura I, Fukuoka M, Mori T. Red degeneration of uterine leiomyoma: MR appearance. J Comput Assist Tomogr. 1994;18(6):925-8.

5. Zaloudek CJ, Hendrickson MR. Mesenchymal tumors of the uterus. In: Blaustein's Pathology of the Female Genital Tract. New York: Springer Verlag. 2002:561-615.
6. Oliva E. Pure Mesenchymal and Mixed Müllerian Tumors of the Uterus. In: Gynecologic Pathology. China: Elsevier Churchill Livingstone. 2009:261330 .

7. Evans AT III, Pratt JH. A giant fibroid uterus. Obstet Gynecol. 1979;54:385-6.

8. Basnet N, Banerjee B, Badani U, Tiwari A, Raina A, Pokharel $\mathrm{H}$, et al. An unusual presentation of huge cervical fibroid. Kathmandu Univ Med J. 2005;3(2):173-4.

9. Suneja A, Taneja A, Guleria K, Yadav P, Agarwal N. Incarcerated procidentia due to cervical fibroid: an unusual presentation. Aust N Z J Obstet Gynaecol. 2003;43(3):252-3.

10. Lugo M, Putong PB. Metaplasia. An overview. Arch Pathol Lab Med. 1984;108(3):185-9.

Cite this article as: Singh G, Verma N, Singh S, Nargotra N. Uterine leiomyoma presenting with unusual pathological features: a series of two cases. Int J Reprod Contracept Obstet Gynecol 2016;5:1266-9. 